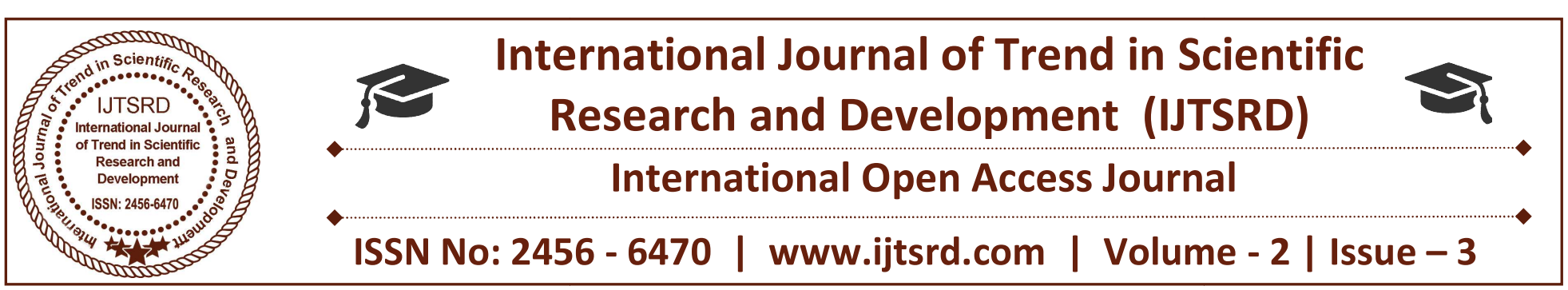

\title{
To Design a Circuit Diagram for Mute Keypad Vocalizer using ARDUINO UNO
}

\author{
Aditi Pandey $^{1}$, Bharti Dewangan ${ }^{2}$, Deepak Pancholi ${ }^{3}$ \\ ${ }^{1,2}$ B.E. Student \\ ${ }^{1,2,3}$ Department of Electronics Communication Engineering, \\ Lakshmi Narain College of Technology, Indore, Indore, Madhya Pradesh, India
}

\section{INTRODUCTION}

Mute input device Vocalizer could be a massive scale microcontroller based mostly system being designed to facilitate the communication among the dumb and deaf individuals by manufacturing a speech and text signal. This system can be dynamically reconstructed to work as a "smart device". In this paper, microcontroller and sensors based mute keypad vocalizer is presented. Mute keypad vocalizer discussed is basically a speaker and a keypad equipped microcontroller based system. Keypad sensor can detect the pressing of keys and microcontroller based system converts some specified key values into speech signals. The vocalizer is equipped with a keypad module and an audio processing unit. This system is beneficial for dumb and deaf people.

Keywords: ARDUINO UNO, Keypad module, Audio processing unit APR 9600 voice recording module, LCD (16*2), ATMEGA 328 p-pu, Speaker unit

\section{INTRODUCTION}

Communication plays an important role for human beings. Communication is treated as a life skill. Keeping these important words in mind we present our paper to help in improving the communication with the deaf and dumb people using keypad module. Generally deaf and dumb people use sign language for communication but it proves to be a barrier while communicating with others who don't understand sign language. This project aims to lower this barrier in communication. A brief description about the mute vocaliser and the implementation part is discussed in this paper. An electronic device is developed that can translate the key information into speech and text in order to make the communication take place between speech impaired deaf and paralyzed patients with the general public possible. Whatever the person wants to communicate is activated by the keypad device. This input is text and is processed using a microcontroller. Further, the frequently spoken words can be stored in the memory of APR 9600 voice chip and can be easily retrieved. The output can be read from the LCD screen by the deaf people and can be heard by the dumb people through a speaker unit

\section{WORKING PRINCIPLE}

The working principle of the mute vocaliser is basically based on four functional units- input unit, audio processing unit, controller unit, and output unit. Whenever the person presses a key of the keypad, a pre-stored message is displayed as well as the message is played through the speaker. The messages are stored in the memory of APR9600 voice chip. Each key has a distinct stored message which can be easily retrieved. In the audio processing unit, APR9600 voice recording chip is used which stores the message and reproduces it back in the sound and text form.

\section{MUTE VOCALISER}

For people with the hearing and speaking disability communication process becomes a big hurdle in their lives. Speaking and listening are the two important skills to communicate. Mute vocaliser is an electronic device designed to eradicate the problem faced by the 
people with the disability to speak and listen. It is a microcontroller based system. A keypad module in the circuit facilitates the system. Whatever the person wants to communicate is activated by the keypad device. This input is text and is processed using a microcontroller. Further, the frequently spoken words can be stored in the memory of APR9600 voice chip and can be easily retrieved. It is a smart device with less complex circuitry and a large message storing capacity which leads to effective communication.

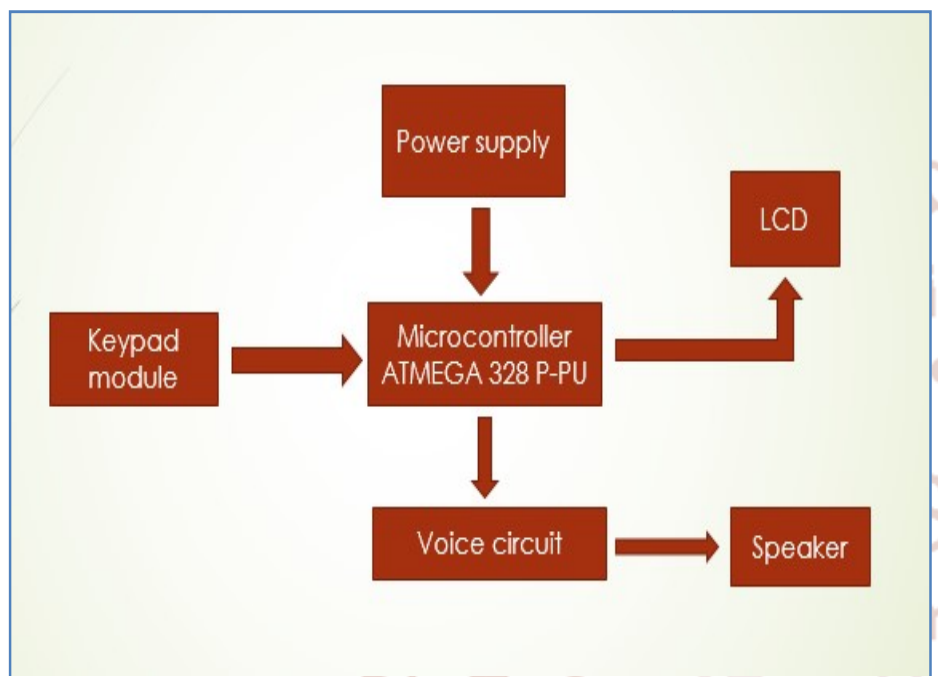

Fig. 1: block diagram of mute vocaliser

\section{A. Keypad module (4*3)}

A $4 * 3$ keypad module is equipped with 10 numeric keys along with two character keys. This module has four rows and three columns. Whenever the person presses a key of the keypad, a pre-stored message is displayed as well as the message is played through the speaker. The messages are stored in the memory of APR9600 voice chip. Each key has a distinct stored message which can be easily retrieved.
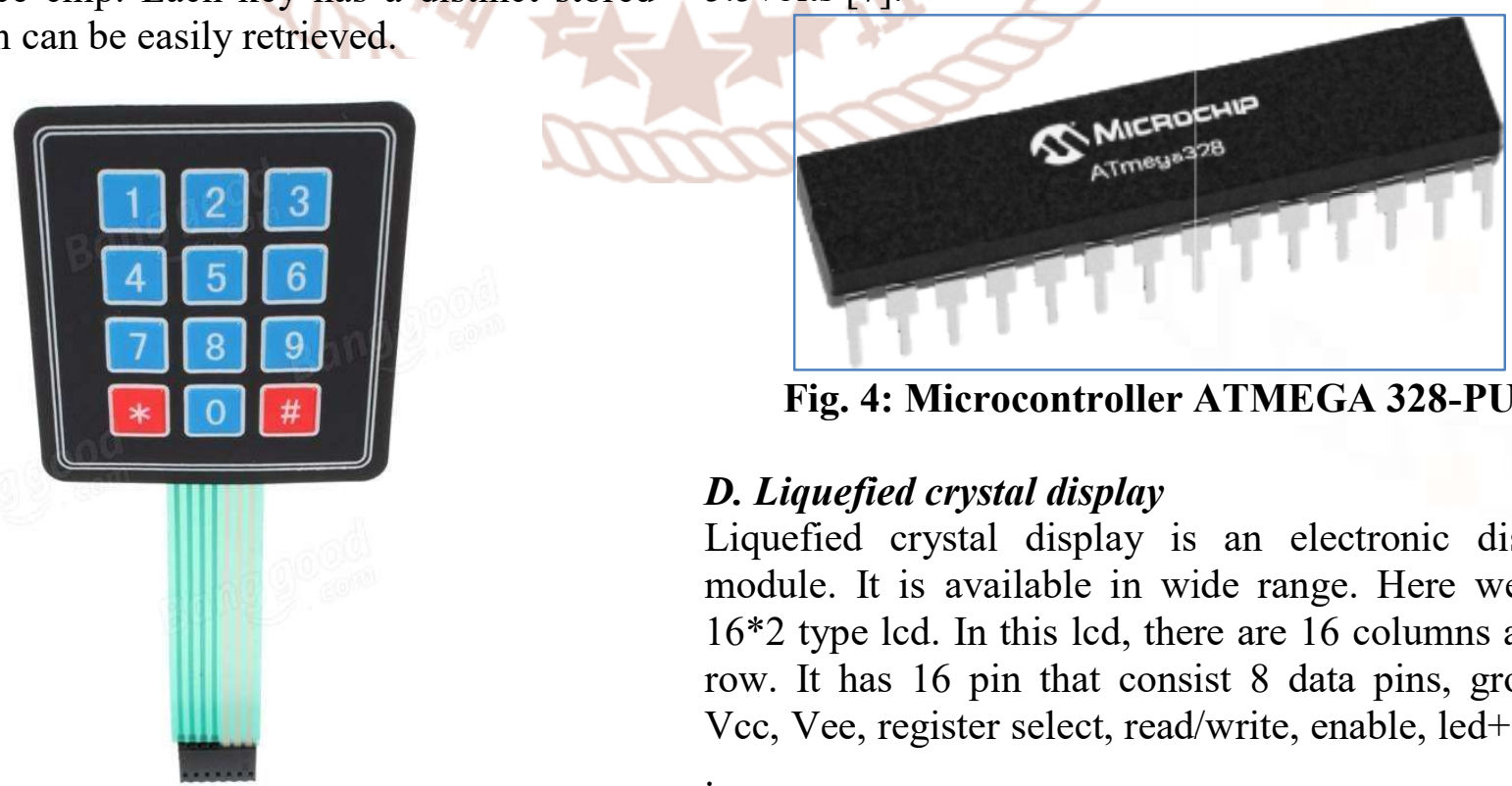

Fig. 4: Microcontroller ATMEGA 328-PU

\section{Liquefied crystal display}

Liquefied crystal display is an electronic display module. It is available in wide range. Here we use $16 * 2$ type $1 \mathrm{~cd}$. In this $1 \mathrm{~cd}$, there are 16 columns and 2 row. It has 16 pin that consist 8 data pins, ground, Vcc, Vee, register select, read/write, enable, led+, led-

Fig. 2: Keypad module $(4 * 3)$ 


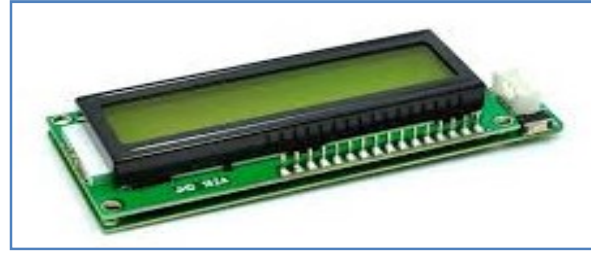

Fig. 5: Liquefied crystal display (LCD)

It is connected with microcontroller to display message.

Library used for coding display in Arduino.

\#include $<$ LiquidCrystal.h $>$

\section{CIRCUIT DESCRIPTION}

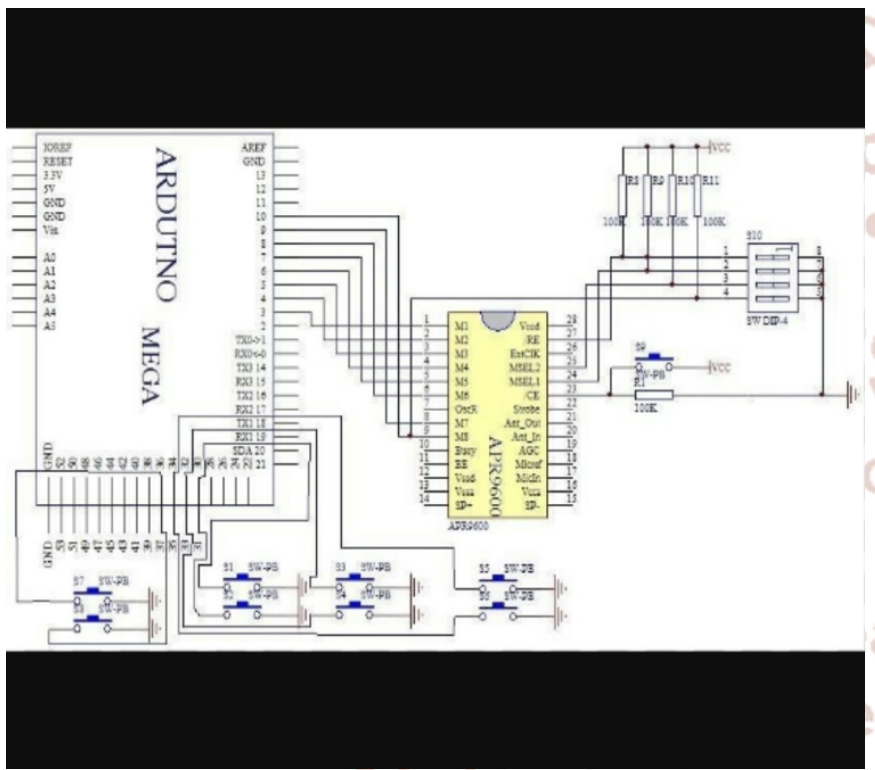

Fig. 6: Circuit diagram of mute vocaliser

The keypad sensor and voice recording module are connected with microcontroller(ATmega328). LCD is connected with pin number $\{7,6,5,4,3,2\}$. Keypad module is connected with the microcontroller. The row pinouts of the keypad connected to the pins $\{19$, $18,17,16\}$ of the ATmega328 microcontroller. The column pinouts of the keypad are connected to the pins $\{15,14,13\}$ of the microcontroller. The audio processing module APR9600 is connected with the pins $\{0,1,8,9,10,11,12\}$ of the microcontroller. The input pins of the keypad module send the key value entered to the LCD unit through the microcontroller ATmega328. The same input is taken to the audio processing unit with the help of microcontroller and band wires. The speech output is obtained through the speaker connected to the output pins of APR9600 voice recording module $\{14,15\}$. The text output is obtained through the LCD unit.

\section{CONCLUSION ENHANCEMENT}

AND

FUTURE

The proposed system translates sign language to speech and text automatically and satisfy mute and deaf people by conveying thoughts on their own. The system overcomes the real time difficulties of people who are not capable to speak and listen and improves their lifestyle. System efficiency is improved with the help of microcontroller and APR9600. By implementing this system speaking dream of dumb people becomes true. Compared with existing system it is possible to carry this system to any places. The main advantage of this approach is less computational time and fast response in real time applications has been achieved. Due to the wireless data transmission to the LCD and recorder, makes the user to handle it freely. It can be used in public places very conveniently. This project plays a major role in various fields such as Robotics, biometrics, automatic control in industries, etc.

In future this project can be made more efficient and compact by designing a gesture controlled vocaliser. It can be made more compact such that both transmitter and receiver parts mounted on a same glove. There can be a lot of future enhancements associated to this research work, which includes:

1. Designing of wireless transceiver system for "Microcontroller and Sensors Based Gesture Vocalizer".

2. Perfection in monitoring and sensing of the dynamic movements involved in "Microcontroller and Sensors Based Gesture Vocalizer".

3. Designing of a whole jacket, which would be capable of vocalizing the gestures and movements of animals.

4. Virtual reality application e.g., replacing the conventional input devices like joy sticks in videogames with the data glove.

5. The Robot control system to regulate machine activity at remote sensitive sites.

\section{REFERENCES}

1. Kiran R, Department of Electronics and Communication Engineering, College of Engineering Trivandrum, India "Digital Vocalizer System for Speech and Hearing Impaired" International Journal of Advanced Research in Computer and Communication Engineering, Vol. 4, Issue 5, May 2015. 
2. Sachin Bhat, Amruthesh M, Ashik, Chidanand Das, Sujith, "Translating Indian Sign Language to text and voice messages using flex sensors", International Journal of Advanced Research in Computer and Communication Engineering, Vol. 4, Issue 5, May 2015.

3. Rajalakshmi, N.Vasudevan, Dr.Rajinigrinath, S. Praveen Kumar, "Electronic Hand Glove Gesture to Voice Reorganization Using Physically Challenged Persons", International Journal of Innovative Research in Computer and Communication Engineering, An ISO 3297: 2007 Certified Organization Vol.3, Special Issue 8, October 2015.

4. Priyanka Lokhande,Riya Prajapati,Sandeep Pansare, "Data Gloves for Sign Language Recognition System"International Journal of Computer Applications (0975 - 8887) National Conference on Emerging Trends in Advanced Communication Technologies (NCETACT-2015).

5. Arulselvi and Tamarai, "Sign Language Recognition System Using Fingern Spelling", Middle-East Journal of Scientific Research 20 (8): 1006-1011, 2014 ,ISSN 1990-9233 ,(C) IDOSI Publications, 2014.

6. Naveen Kumar Toshawar, Chandni Jain, "Intelligent Control System using Gesture Sensing", National Conference on Synergetic Trends in engineering and Technology: Impact of Industry \& Society (STET-2014) International Journal of Engineering and Technical Research (IJETR) ISSN: 2321-0869, Special Issue.

7. Vajjarapulavanya, Akulapravin, M.S., Madhanmohan, "Hand Gesture Recognition And Voice Conversion System Using Sign Language Transcription System" IJECT Vol. 5, Issue 4, Oct - Dec 2014.

8. R.Manikandan Sastra University, Sign Language to Speech Translation System Using PIC Microcontroller,http://www.researchgate.net/publi cation/236582497, APRIL 2013.

9. Ajinkyaraut, Vineeta Singh, Vikrant Rajput, ruchikamahale "HAND SIGN INTERPRETER" The International Journal of Engineering And Science (IJES), Volume 1, Issue 2, Pages 19-25, 2012, ISSN: $2319-1813$.

10. Bhavina Patel, Vandana Shah, Ravindrakshirsagar, "Microcontroller Based Gesture Recognition System for the Handicap
People", Journal of Engineering Research and Studies, Vol. II, Issue IV, October-December, 2011/113115.

11. Muhammad Ali Mazidi, Janice Gillispie Mazidi, Rolin D Mckinenlay, "The 8051 Microcontroller and Embedded systems" published by Pearson Education, Second Edition, 2008. 